ARTICLE

\title{
Skills Training and Employment Outcomes in Rural Bihar
}

\author{
Bhaskar Chakravorty ${ }^{1} \cdot$ Arjun S. Bedi $^{2}$ (1)
}

Published online: 8 July 2019

(c) The Author(s) 2019

\begin{abstract}
In a number of countries, youth unemployment is a pressing concern. In India, 54\% of the country's population is below the age of 25 and faces a high rate of (disguised) unemployment. To augment youth employment, the Government of India has launched a number of skills training programs. This paper deals with participation in and the impact of one of these programs [Deen Dayal Upadhyaya Grameen Kaushal Yojana (DDUGKY)] located in rural Bihar, one of India's poorest states. The analysis is based on data collected in mid-2016 and compares trained participants with non-participants who applied for the scheme but eventually did not attend. We find that the training program squarely reaches the intended target group - rural poor youth. Initially, the program leads to a 29 percentage point increase in the employment rate of the trained graduates. However, 2-6 months after the training, the employment effect of the program drops to zero. A third of the placed graduates leave their jobs due to caste-based discrimination, and another third leave due to a mismatch between the salaries offered and their living costs. The upshot is that while the training program enhances job market prospects, other labor market factors undo the positive effects.
\end{abstract}

Keywords India $\cdot$ Bihar $\cdot$ Skills training $\cdot$ Youth unemployment

JEL Classification J60 $\cdot$ J68

Arjun S. Bedi

bedi@iss.nl

Bhaskar Chakravorty

B.Chakravorty@warwick.ac.uk

1 Warwick University, Coventry, UK

2 International Institute of Social Studies, Erasmus University Rotterdam, Kortenaerkade 12, 2518 AX The Hague, The Netherlands 


\section{Introduction}

According to the 2013 World Development Report (WDR), worldwide, some 200 million people, including a disproportionate share of about 75 million who are below the age of 25 are unemployed and actively looking for work. The report goes on to argue that over 600 million jobs will be needed in the next 15 years to absorb the increase in the working-age population, mainly in Asia and Sub-Saharan Africa.

The issue is not only one of unemployment, but is exacerbated by the large proportion of individuals working in the informal economy. Indeed, half of all workers in developing countries are engaged in small-scale agriculture or self-employment, jobs that don't provide steady pay-checks and benefits. One of the challenges in addressing youth unemployment is the low level of formal schooling compounded by the skills gap - that is, the gap between the skills needed by employers and the existing skill set of job seekers.

India is an example of a developing country facing a pressing need to devise strategies to provide regular employment to its youthful population. ${ }^{1}$ India is among the youngest nations in the world, and the expected 'bulge' in the 15-59 age group over the next decade offers an opportunity but also a challenge. The opportunity stems from the expected global shortage of 56 million young people (15-35 years), and India could potentially serve as a worldwide sourcing hub for skilled manpower (Ministry of Labour and Employment 2014). On the other hand, a failure to provide opportunities to the youth population as they enter the labor market may translate into a 'demographic disaster' rather than a dividend (Mitra and Verick 2013).

The twin challenges of creating jobs while at the same time bridging the skills gap are well recognized by the Indian Government. Consistent with this policy priority, on September 25, 2014, the Government launched the 'Deen Dayal Upadhyaya Grameen Kaushal Yojana' (DDUGKY), a program for training, skill building and job placement intended for rural youth from poor families. The vision of the program is to:

Transform rural poor youth into an economically independent and globally rel-

evant workforce (Ministry of Rural Development 2016).

The scheme implements skill development through a public-private partnership mode, whereby registered private sector partners or project implementation agencies (PIA) plan and implement skills training and place program participants. The DDUGKY is not an entitlement program but rather eligible candidates decide whether to participate or not, in government-sponsored training programs. Candidates in the age group 15-35 are eligible to participate if they belong to the belowpoverty-line (BPL) category or if any member from their family is a member of a

\footnotetext{
1 With a population of 1.21 billion of which more than $62 \%$ are in the working-age group of $15-59$ years and more than $54 \%$ are below 25 years, India is among the youngest nations in the world (Ministry of Skill Development and Entrepreneurship 2015).
} 
self-help group (SHG). ${ }^{2}$ If neither of these conditions are met, then an applicant needs to provide a letter of recommendation from the Gram Panchayat (Ministry of Rural Development 2016). ${ }^{3}$

The intention of the DDUGKY and other similar programs is to attenuate unemployment and poverty, but this is possible only if social structures do not hinder voluntary participation in the program. If there are differences in program access based on caste, gender or other social markers, either in program participation or in job placement after training, then increasing government spending and augmenting the supply of trained individuals may achieve little toward the final goal of enhancing welfare and equity. Hence, from a policy perspective, it is important to examine both the factors promoting or hindering scheme participation and to identify the impact of the scheme on employment prospects and earnings.

Despite the large number of skills training and employment programs operating in India, and the considerable resources expended on such schemes, systematic evaluations of their impact on creating employment as well as assessing whether such schemes reach the intended population, are limited. This paper offers such an analysis. Based on both, survey and qualitative data, collected in a district in North Bihar, this paper examines the role of socio-economic and demographic characteristics in determining scheme participation. Subsequently, we evaluate the effect of scheme participation on employment and earnings.

Although the study focuses on one course offered through a government-sponsored program, that is, the DDUGKY, it has much wider applicability as similar programs are being implemented in various parts of the country. For instance, another important skill-building program is the 'Pradhan Mantri Kaushal Vikas Yojana' (PMKVY) which is almost similar to DDUGKY and is also being implemented by the central government. In addition, various state-specific programs such as 'Himayat' (for rural youth in Jammu \& Kashmir), 'Roshni' (rural youth in 27 left-wing extremist districts across 9 states) and 'Star' (Standard training assessment and reward scheme) are also being implemented.

The rest of the paper unfolds by providing in Sect. 2 a review of the existing literature on youth training programs with a focus on schemes operating in developing countries. Section 3 provides an overview of the DDUGKY. Section 4 discusses the sampling strategy and data collection, while Sect. 5 outlines an analytical framework, presents results and explores the financial returns from the program. Section 6 contains concluding remarks.

\footnotetext{
${ }^{2} \mathrm{BPL}$ is used by the Indian government to identify individuals and households in need of government assistance. Internationally, an income of less than $\$ 1.90$ per day per head in purchasing power parity terms is defined as extreme poverty. In India, the number of people living on or less than $\$ 1.90$ per day based on the 2011 census was 259.5 million (21.3\% of the population). In India, BPL scoring is done on the basis of 13 parameters ranging from 0 to 4 . Families that score 17 or less out of 52 are classified as BPL.

3 A gram panchayat is a village-level administrative body whose main task is to implement development programs. It is part of a three-tier Panchayati Raj Institution (village, block and district level) created by the 73rd amendment of the constitution. There are about 250,000 gram panchayats in India.
} 


\section{Skills Training Programs in Developing Countries: A Brief Review}

There is a large and active body of research using a variety of methodological approaches on the effect of skills training programs on employment outcomes and earnings in OECD countries. For instance, Björklund (1994) and Forslund and Krueger (1997) provide early reviews of the evidence based on Sweden's experience with such programs, while Heckman et al. (1999) review the US literature. ${ }^{4}$ Based on the US experience, Heckman et al. (1999) conclude that job training programs have modest positive effects on adult earnings and no impact on the youth. These early reviews have been followed by multi-country reviews of experiences in other OECD countries. For instance, De Koning (2005) reviews 130 studies while Kluve (2010) assesses the effects of active labor market programs including skills training programs based on 73 microeconomic evaluations carried out in Europe. De Koning (2005) concludes that training interventions have no effect on unemployed young workers while Kluve (2010) writes that 'traditional training programs are found to have a modest likelihood of recording a positive impact on post-program employment rates' but that programs targeted at the youth are less successful. Meager (2009) assesses the various review articles and concludes that the impact of vocational training programs is modest, at best, and that only small-scale programs targeted at groups experiencing a skill shortage coupled with active employer engagement and on-the-job training are likely to be effective at enhancing employment prospects. Kluve (2010) reports that 'program type is by far the most important variable influencing post-program employment probabilities' and with regard to the effectiveness of training programs as compared to other active labor market programs (ALMP) he states 'training measures sit in the middle of the hierarchy: neither the most effective measures, nor the least.' Meager (2009) also argues that is not 'generally the case' that larger impacts are observed over a longer post-intervention period while at the same time pointing out that the lack of skill-training effects may be due to slack labor demand, especially in developed countries where skill levels are already high.

Till recently, most of the evidence regarding the effectiveness of skills training programs came from developed and transition countries. However, there is now a growing body of work on developing countries. In their first study, Dar and Tzannatos (1999) covered 72 evaluations but almost all of them focused on developed countries. However, their updated work (Betcherman et al. 2004) added 39 additional evaluations from developing and transition countries including 19 evaluations of youth training programs of which 14 were from developed countries and five from developing countries. Betcherman et al. (2004) review of the effects of the five youth training and employment generation programs in Latin America shows that in contrast to the zero effects of such programs in developed countries, all the Latin American interventions report a positive effect on the probability of employment

\footnotetext{
4 Active labor market programs were initially developed in Scandinavia and thereafter spread to other OECD countries (Meager 2009).
} 
and two of the three reported positive impact on earnings. ${ }^{5}$ The sharp difference in findings across different contexts is perhaps not unexpected as trainees in developing countries have lower levels of formal education and skills, and it is quite likely that their employability is hampered by a shortage of skills. While the experiences based on these schemes are encouraging, the picture emerging from several recent randomized evaluations of training programs targeted at disadvantaged youth does not yield such a sanguine picture. ${ }^{6}$ For instance, Card et al. (2011) and Ibarrarán et al. (2014) analyze the impact of a vocational training program in the Dominican Republic, while Cho et al. (2013) analyze the effect of an intervention in Malawi. In both countries, reminiscent of the developed country literature, the interventions have no effect on employment. Attanasio et al. (2011) find mixed evidence in the case of Colombia, where training leads to a 7 percentage point increase in employment and a $20 \%$ increase in earnings, but only for young women. In contrast to the womenonly effect in Colombia, Alzua et al. (2016) find large effects for men in the case of a youth training program in Cordoba, Argentina. Their randomized evaluation based on a sample size of 407 individuals (220 treatment and 187 control) participants who were followed for a long period shows that in the short term (18 months after the program), program participation increases the probability of employment by 8 percentage points and earnings by about $40 \%$. However, these effects do not last and dissipate in the medium term (33 months) and long term (48 months). ${ }^{7}$ McKenzie (2017) review this recent literature which includes 12 evaluations of skill-building training programs from eight countries. Typically, the evaluations measure impact 12-18 months after the conclusion of the training program. Three of the nine studies find a statistically significant impact on employment. The simple unweighted average across the studies is a 2.3 percentage point increase in employment. There is a slightly larger impact on formal employment - the average impact across the studies is a 3.6 percentage point increase in formal employment.

In the Indian context, we were unable to find studies that have estimated the impact of youth skills training programs sponsored by the government. Although not offered by the government, an experimental study designed by Maitra and Mani (2017) and implemented in co-operation with non-governmental organizations offers estimates of the impact of a 6-month stitching and tailoring training program targeted at young women (aged 18-39 years) in New Delhi. The paper examined the

\footnotetext{
5 The youth training employment programs (Joven) in Latin America were initiated in Chile in 1991, and thereafter, similar programs have been implemented in Argentina, Colombia, Peru, and Uruguay. The various programs target youth from low-income families, with low educational attainment, and with limited or no job experience. The programs consist of basic literacy, training in a trade which is in demand, work experience, and help finding a job. Typically, the intervention lasts for 6 months and includes 200-400 h of training and 2-3 months of work experience.

${ }^{6}$ Other experimental evaluations of vocational training program in developing countries include Acevedo et al. (2017) for the Dominican Republic, Attanasio et al. (2017) for Columbia, Maitra and Mani (2017) for India, Diaz and Rosas (2016) for Peru, Honorati (2015) for Kenya.

7 Although their paper does not focus on disadvantaged youth but on the general unemployed population, Hirshleifer et al. (2016) use a randomised experiment to assess the effect of a large-scale vocational training program in Turkey and conclude that the effect of being assigned to training had a 2 percentage point, but statistically not significant effect on the probability of being employed.
} 
impact of the program 6 months and 18 months after program completion on a sample of 594 women (409 treatment and 185 control). According to the study's findings, in the short term, women who received training were 4 percentage points more likely to be self-employed, 6 percentage points more likely to be employed and earn $150 \%$ more per month as compared to the control group. The effects persisted in the medium term. While the effects are impressive, the authors report that only $56 \%$ of those assigned to treatment completed the course and that there were a number of barriers to entry, chiefly, lack of access to credit, lack of child-care support and the distance from residence to the training center.

This paper analyses the effect of a training program sponsored by the DDUGKY on employment and earnings. While it is not based on an experiment, the empirical approach which is based on comparing participants with non-participants who expressed a desire in the scheme but did not eventually join, yields an arguably credible design. We work with what may seem like a relatively small sample of 526 respondents, but it is large as compared to the total pool of trained participants and the sample size is comparable to those in Alzua et al. (2016) and Maitra and Mani (2017).

The paper is a potentially useful addition to the literature and policy debates on the relevance and usefulness of such training schemes. It offers perhaps the first estimates of the impact of a training course sponsored by the DDUGKY. Given the resources expended on the DDUGKY and similar programs, an assessment of their effectiveness in generating employment and the cost at which they do so is sorely needed. Second, the bulk of the international literature focuses on youth training programs for disadvantaged urban youth, while this paper focuses on disadvantaged rural youth living in one of India's poorest states, that is, a group which is more likely to face a skills gap as well as other challenges compared to urban youth. ${ }^{8}$ In principle, this is a target group for whom such skills training programs should be particularly effective.

\section{DDUGKY}

On September 2014, under the aegis of its National Rural Livelihood Mission, the Ministry of Rural Development (MoRD) announced the DDUGKY. The scheme targets rural families who fall below the poverty line. Individuals from such families who are in the age range 15-35 are eligible for government-sponsored training and post-training job placement in positions that offer regular monthly wages. ${ }^{9}$

The DDUGKY skilling ecosystem consists of The Ministry of Rural Development (MoRD) or the National Mission Management Unit (NMMU), State Missions,

\footnotetext{
${ }^{8}$ For instance, in urban settings, information on the job market and accessibility to training programs may be more readily available; thus, the primary determinants for decision making may be individual competitiveness and attitude. However, in a rural setting, information barriers may be more binding and accessibility to training programs may depend on gender, caste or class.

9 Additional details are available on http://ddugky.gov.in/.
} 
Project Implementing Agencies (PIA) and Technical Support Agencies (TSA). The MoRD is responsible for framing policy, monitoring the scheme and in collaboration with state governments, responsible for providing funds. ${ }^{10}$ Identification of courses to be offered is based on skills gap assessment studies carried out by the National Skill Development Corporation (NSDC) as well as inputs from state missions. On the basis of these studies, DDUGKY invites tenders from private sector partners who wish to provide training. State missions are responsible for planning and implementing the program through the private sector PIA. The PIA are responsible for identifying prospective applicants, providing information on the training courses, delivering training and placing the trained graduates.

To elaborate, the PIA begins the implementation process by embarking on a process of community mobilization and awareness building using different modes such as awareness camps, job fairs, placing banners, distributing handbills and pamphlets and door-to-door counseling. PIA also involves village self-help groups (SHG) and gram panchayats (GP) in their efforts to reach out to eligible candidates. After mobilization, candidates who have indicated an interest in a training program are asked to complete a field registration form and are then invited for counseling. During counseling, candidates and in some instances, their parents are given information on the nature of work in the selected sector, availability of jobs, growth prospects and the challenges. The counseling sessions are also used to determine whether the applicants fulfill eligibility conditions. After counseling, the list of selected candidates is sent for approval to the state missions, and once approved, the candidates may join the training program.

Each course offered through the DDUGKY consists of two broad components. The first component includes training on soft skills, English and information technology and the second component deals with sector specific training. Depending on the course, the duration of training may be for 3 (576 h), 6 (1152 h), 9 (1578 h) or 12 months $(2304 \mathrm{~h})$. The scheme provides for on-the-job training (OJT) ranging from a maximum permissible 30 days for a 3-month course to 120 days for a 1-year course. The training courses offered by the PIA have to be approved by the National Council for Vocational Training (NCVT) or Sector Skill Councils (SSCs). These TSA also provide support in terms of designing the curriculum and certifying the trained graduates. ${ }^{11}$

Post-training, PIA are required to place a minimum of $70 \%$ of trained individuals in jobs which offer regular monthly wages at or above a minimum monthly wage of Rs. $6000 .{ }^{12}$ The scheme has provisions for post-placement financial

\footnotetext{
10 The bulk of the funding, 75\%, comes from the central government through the MoRD and the remainder from state governments, except for the North-Eastern states where central funding accounts for $90 \%$.

11 Two types of quality controls assessments are mandated under DDUGKY. The first is an internal and continuous assessment, which is conducted by PIA on a regular basis and monitored by the states government on a bimonthly basis. The second is third-party assessment and certification of trainees by agencies approved by the National Council for Vocational Training (NCVT) or Sector Skill Councils (SSCs). It is mandatory for $70 \%$ of the trained candidates per batch to be certified.

12 Prior to project approval, PIAs are required to submit a tentative list of employers to the DDUGKY administration. This list is part of the PIA's proposal, but the jobs actually provided to candidates may or may not be the same as those on the proposed list. In practice, the placement officer of the PIA liaises
} 
support. ${ }^{13}$ To enhance employment sustainability, all trained/placed candidates are tracked for 1 year. During this year, they are also entitled to counseling and guidance.

As of 2016, DDUGKY operates in 21 States/Union Territories, covering 568 of India's 687 districts. The scheme offers about 690 courses in more than 330 trades catering to 82 industry sectors. The training is offered through over 300 private training partners. According to the latest reports, over 270,000 candidates have been trained and over 134,000 candidates have been placed in jobs. Since its inception, DDUGKY has invested more than Rs. 56 billion or about USD 838 million. ${ }^{14}$

Based on the USD 838 million spent since scheme inception and the number of individuals trained $(270,000)$, the average amount spent per trained individual is about USD 3100 or Rs. 217,210. If this is restricted to those who have been placed, then the average cost per placement is USD 6250 or Rs. 437,710. Details on the minimum and maximum fee that may be charged by a PIA for training candidates are provided in Table $1 .{ }^{15}$

\section{Sampling Approach and Data}

The sampling and data collection approaches were developed in collaboration with a local NGO, which is also a DDUGKY implementing partner. ${ }^{16}$ The district where the data collection was carried out is located in North Bihar and was selected as the first author is conversant with the social context and the language and also because the selected district started implementing the scheme in 2014 which provides a sufficient number of trained individuals to carry out an evaluation. The selected district is not particularly different from other rural areas of Bihar. The bulk of the

\footnotetext{
Footnote 12 (continued)

with potential employers using all possible networks on a continuous basis. Post-placement, proof of regular wage has to be demonstrated either by a salary slip from the human resource department of the organization or in the absence of a human resource department, a certificate issued by the employer indicating wages paid and counter signed by the employee along with a bank statement.

13 Candidates are entitled to post-placement financial support through the PIA. An amount of Rs. 1000 per month is available for 2 months in case the placement is within the district of residence; Rs. 1000 per month for 3 months if placement is outside the district but within the state of residence; and Rs. 1000 per month for 6 months if placement is outside the state of residence.

$14 \mathrm{http} / / /$ ddugky.gov.in/content/about-us-0.

15 There are separate budget lines for the cost of training, boarding and lodging costs for residential training, transport costs for non-residential training, post-placement tracking and support, incentives for the PIA for placement and post-placement activities, assessment and certification.

16 To ensure confidentiality, we do not reveal the name of the district or the name of the local NGO. However, we do have information which provides an idea of the quality of training provided by the NGO. The NGO has 19 employees of which 7 are trainers. The lead trainer has a B.A. in Business Administration and a M.A. in Social Work. There is a dedicated soft skills trainer with a B.A. degree; two trainers who specialize in retail sales training both of whom have M.A degrees in Business Administration and an IT trainer with a B.A degree, a 1-year computer diploma and several short diploma courses. In short, on paper, the NGO seems to have enough well-trained personnel to deliver a quality program.
} 
population is engaged in agriculture, non-farm opportunities are limited, and caste remains a dominant social marker (Table 2).

The NGO provided a complete list of 520 individuals who had participated in its 3-month $(576 \mathrm{~h})$ residential retail sales training course and a complete list of an additional 721 applicants who had shown an explicit interest in the course and had filled the field registration form but subsequently did not pursue the process and did not participate in the course. ${ }^{17}$ The lists were checked to ensure that there were no duplicates and that program participants did not also appear in the list of program non-participants and vice versa. Keeping in mind statistical (see note below for details on power calculations) and budgetary considerations, about $50 \%$ of the participants (263 participants) and an equal number of non-participants were randomly sampled, yielding a total sample of 526 participants and non-participants. ${ }^{18}$

Data collection was carried out between July and August 2016 by a team led by the first author. The survey instrument gathered information on a range of individual and household socio-economic and demographic characteristics including questions on the respondent's religion, caste, age, sex, years of education, occupation, income and membership of various social programs. In addition, information on the same characteristics was also collected for parents of the respondents as well as on their land holdings and housing characteristics.

The survey gathered information on current (post-training) employment and earning status of participants and non-participants, that is, between 2 and 6 months after completion of the course. We also enquired whether they were offered jobs after training, as well as their employment and earnings status at the time that individuals applied for the training programs (pre-training). Thus, we have information on employment outcomes at three points in time, that is, pre-training, immediately after training, and 2-6 months after training. The pre-training information and immediate post-training employment and earnings status are both based on recall which may raise concerns about the quality of the data. However, given the short duration of the course and the relatively short time-span between program inception and the survey this is unlikely to be a problem. At most, respondents were being asked to recall their employment and earnings 9 months before the survey. ${ }^{19}$

\footnotetext{
17 The NGO offers only a 3-month course, and participants do not have an option to choose the duration of the course.

${ }^{18}$ Based on an employment rate of $10 \%$ for the control group (see Maitra and Mani 2017) and a modest expected effect of a 10 percentage point increase in post-training employment, a sample size of 526, equally split between participants and non-participants and $5 \%$ probability of making a type I error has a power of 0.87 . The expected effect may seem large as compared to the effects reported in the literature, but it is close to the 8-10 percentage point effect on employment as reported in Maitra and Mani (2017) and Alzua et al. (2016). Given the nature of the intervention which is expected to achieve 70\% postprogram job placement, the expected effect size used to compute power is very modest.

19 The most recently trained batch had graduated 2 months prior to the survey, and the first trained batch had graduated 6 months prior to the survey. Taking into account the duration of the course, it implies that pre-training or pre-application information regarding employment and earnings is based on recall periods of 5 to at most 9 months prior to the survey.
} 
Table 1 Cost per candidate

\begin{tabular}{|c|c|c|c|c|}
\hline Duration in months & 3 & 6 & 9 & 12 \\
\hline Minimum cost per candidate (Rs.) & 37,439 & 69,778 & $1,03,116$ & $1,35,455$ \\
\hline $\begin{array}{l}\text { Maximum cost per candidate including } \\
\text { incentives for PIA (Rs.) }\end{array}$ & 89,197 & $1,41,795$ & $1,95,392$ & $2,47,990$ \\
\hline \multicolumn{5}{|l|}{ For non-residential training } \\
\hline Minimum cost per candidate (Rs.) & 30,689 & 56,278 & 82,866 & 108,455 \\
\hline $\begin{array}{l}\text { Maximum cost per candidate including } \\
\text { incentives for PIA (Rs.) }\end{array}$ & 81,197 & 115,795 & 151,392 & 185,990 \\
\hline
\end{tabular}

In addition to the structured survey, the instrument contained a set of open-ended questions which asked participants why they enrolled and likewise asked non-participants why they did not enroll. Additionally, for those who had been offered jobs after training and were no longer working, we also enquired why they had not continued with the jobs that they had been offered.

\section{Analytical Framework}

\subsection{Participation in the DDUGKY}

The scheme is intended for rural poor youth and the first issue that we examine is whether the program reaches its intended target group. Since the scheme is intended for below-poverty-line (BPL) families and/or if any household member participates in a self-help group (SHG), in addition to analyzing the role of several individual and household socio-economic and demographic characteristics, we explicitly examine the link between being a BPL or a SHG household and program participation.

Specifically, the probability that an individual $(i)$ joins the scheme $(D D U G K Y=1)$ is treated as a function of individual characteristics $(I)$ including, sex, age, years of education, religion and caste of the applicant; household characteristics $(H)$ include age and education of parents, father's occupation, land holdings, ownerships of house, type of house, monthly income, BPL card holder and whether any member of the household is a member of a self-help group. To control for supply side effects $(S S)$, we also control for distance to the training center. Accordingly, the probability of enrolling in the training scheme is scheme is written as,

$$
p\left(\text { DDUGKY }_{i}=1\right)=f\left(\alpha I_{i}, \theta H_{i}, \beta S S_{i}, \varepsilon_{i}\right)
$$

and several variants of (1) are estimated using a probit specification.

\subsection{Impact of DDUGKY}

Given the voluntary nature of the $D D U G K Y$, there are two key econometric issues which require discussion while attempting to identify its impact. These are 


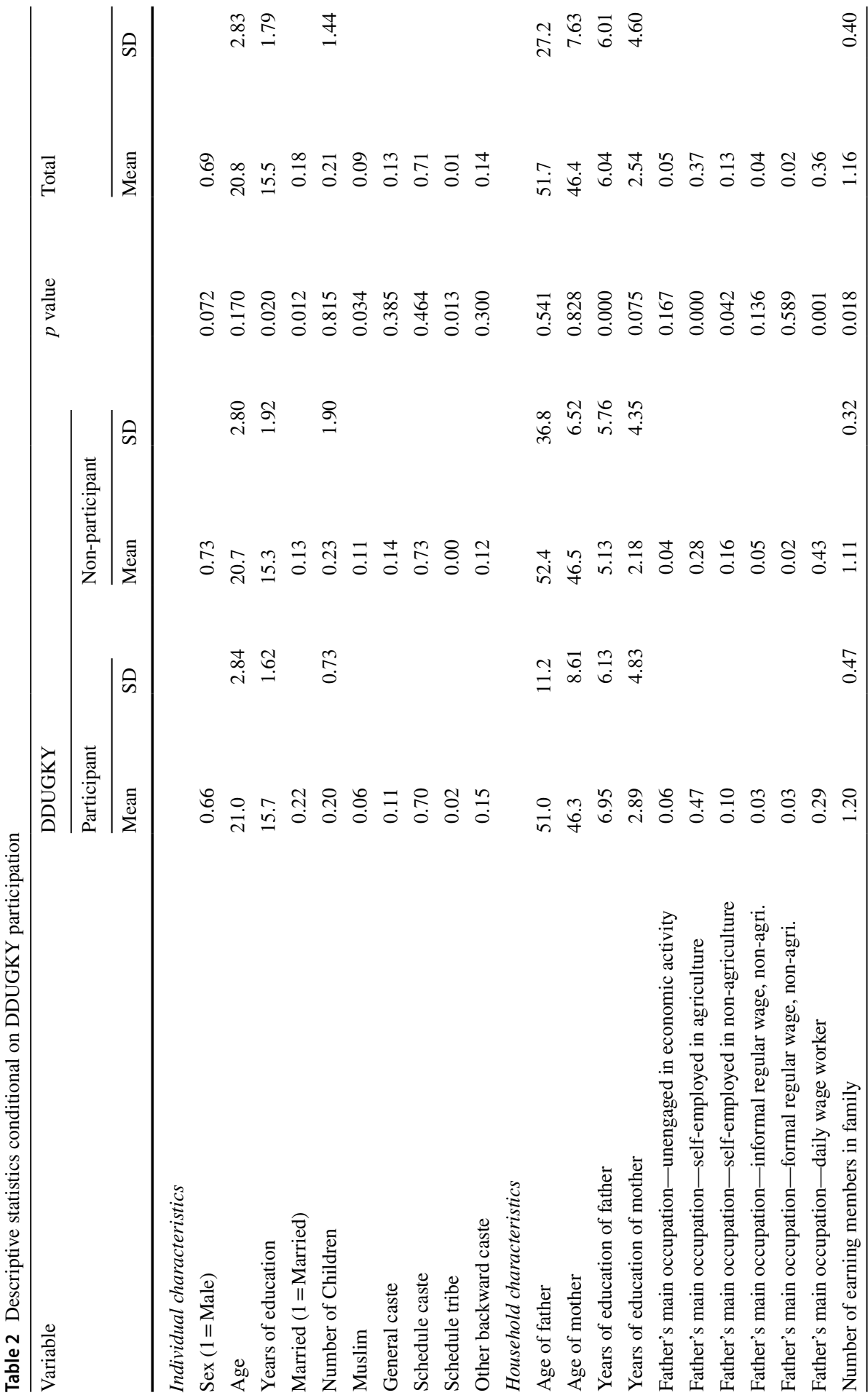




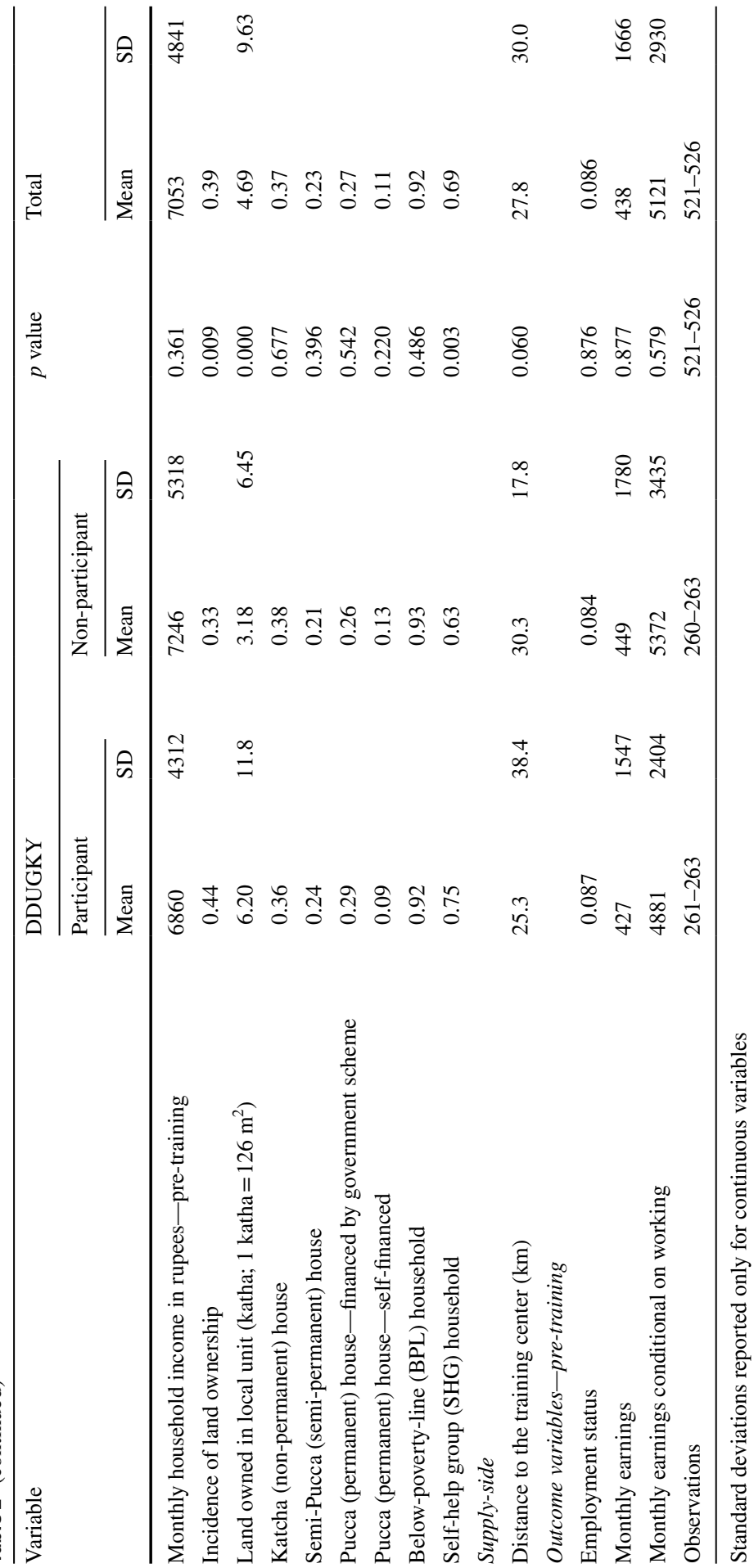


self-selection into program participation and attrition or dropping out before completion of training. To deal with the former, especially selection on unobservables, we use a control group of non-participants randomly drawn from a sample of individuals who registered for the program but did not eventually join. The use of such a control group is expected to reduce differences in unobservable traits between the program participants and non-participants. A second source of concern is that not all participants complete the program. If only a select few complete the program, then evaluating program outcomes on the basis of comparisons between non-participants and participants who complete a program may lead to misleading inferences. Our examination of the administrative records shows that while it is not negligible, the dropout rate is not particularly high and that $87 \%$ of those who start do complete. This should not be surprising as the training program lasts for 3 months.

With this background in mind and given the data at hand, there are two approaches that may be used to assess the impact of the DDUGKY. First, we propose to rely only on the current (post-training) outcomes and estimate the effect of having received training on employment and earnings $\left(y_{i}\right)$, after controlling for individual and household characteristics. That is,

$$
y_{i}=f\left(\alpha I_{i}, \theta H_{i}, \beta \mathrm{DDUGKY}_{i}, \varepsilon_{i}\right),
$$

where $\beta$ is the coefficient of interest. We estimate (2) using OLS and explore the sensitivity of the estimates to alternative estimators such as propensity score matching inverse probability weighting and instrumental variable (IV) estimation. In the case of all three alternatives, the first-step involves estimation of the probability of participation based on (1). ${ }^{20}$ The use of a control group as discussed above to account for selection on unobservables and the use of statistical methods to control for differences in observables is likely to yield credible estimates. However, it is still possible that those who joint the program and completed it are different in terms of their unobserved characteristics as compared to who did not join the scheme. For instance, participants who join and complete may be more motivated or more able which may also affect their chances of finding employment and may lead to inflated estimates of program effects on outcomes. While the direction of the bias is not always clear, it is possible that, $\operatorname{Cov}\left(\operatorname{DDUGKY}_{i}, \varepsilon_{i}\right) \neq 0$.

An alternative, since we have information on pre-training and post-training outcomes, is to estimate a value-added or panel data version of (2). That is, we estimate the extent to which changes in employment and earnings may be attributed to participation in DDUGKY after controlling for time $\left(\lambda_{t}\right)$ and individual fixed effects $\left(\eta_{i}\right)$. That is,

$$
y_{i t}=f\left(\beta \mathrm{DDUGKY}_{i t}, \lambda_{t}, \eta_{i}, \varepsilon_{i t}\right) .
$$

This specification will yield unbiased estimates of the program on employment and earnings, as long as participation and outcomes are driven by timeinvariant unobserved characteristics. However, if the two groups (participants and

\footnotetext{
${ }^{20}$ In the case of the IV estimator, we rely on differences in functional form for identification. Alternative specifications based on imposing exclusion restrictions did not yield different results.
} 
non-participants) are exposed to different time-varying idiosyncratic errors then estimates based on (3) are still likely to be biased. While this is unlikely, given that both groups reside in the same district and there is a fairly short time-span between pre- and post-training, it remains a possibility.

\subsection{Results}

\subsubsection{Descriptive Statistics}

Table 2 provides descriptive statistics. These statistics allow us to gauge whether the training program does target the rural poor and also to examine whether our empirical approach, which is based on comparing those who participate in the training program versus those who expressed an interest but did not finally participate, delivers a credible control group.

The average individual who has shown an interest (that is, both those who attend and do not attend) in the training programs is about 21 years old and has about 15 years of education. The majority of the sample $(69 \%)$ is male, and a similar proportion $(71 \%)$ falls in the category of scheduled caste/tribe (SC/ST). Almost all the respondents $(92 \%)$ belong to below-poverty-line households, and $37 \%$ live in nonpermanent houses. Only about $9 \%$ report that they are employed and conditional on being employed they earn about Rs. 5000 a month. The main point emerging from the descriptive statistics is that the training program is clearly well-targeted at rural poor households. For instance, the proportion of SC/ST in the sample is substantially higher than the proportion for Bihar (17.3\% according to Census 2011). Similarly, the estimated head count ratio of poverty in rural Bihar is $34.3 \%$ (Reserve Bank of India, 2016), while in the sample it is more than $90 \%$.

With regard to the individual traits of the respondents, comparison of means across the two groups shows that there are no statistically significant differences in terms of the outcome variables across the two groups. Both groups are equally likely to be employed and conditional on employment have, on average, the same monthly earnings. Age and caste composition is also similar. While the difference in educational attainment is statistically significant, the difference is not substantial, 15.7 years of education for participants versus 15.3 for applicants. There are differences in the gender composition with a smaller proportion of males $(66 \%)$ in the training group (66 vs. $73 \%$ ) and at the same time those who opt for training are more likely to be married ( 22 vs. $13 \%$ ). With regard to their household background-both groups are equally likely to belong to below-poverty-line households, their household incomes are similar and they also have access to the same housing infrastructure. There are differences in the educational and occupational backgrounds of their parents. Those who attend training have more educated fathers ( 7 vs. 5 years) who are more likely to be self-employed in agriculture. Consistent with the difference in occupational distribution, their families also own more land (6 vs. 3 kathas). Although the training course that they attend is residential, participants live about $5 \mathrm{~km}$ closer to the center than non-participants (25 vs. $30 \mathrm{~km})$. 
Overall, while not perfectly balanced, the approach of comparing those who participate versus those who register for the program but finally do not join appears to deliver an arguably credible control group. Differences across the two groups are not very pronounced. Most notably, before the training, the two groups are similar in terms of their employment and earnings outcomes as well as their caste, BPL, household income and housing quality status. There are differences in parental education, father's occupation and agricultural land holdings; however, these are likely to be time-invariant and may be partialled out while estimating the effect of training on changes in employment and earnings.

\subsubsection{Program Participation}

Notwithstanding the discussion of the participant-specific descriptive statistics which provide an idea of factors that influence participation, formal estimates of program participation are provided in Table 3. Consistent with the descriptive statistics, across the various specifications-education-both of the respondent and the father of the respondent are positively associated with participation. Married individuals are 11-15 percentage points more likely to participate perhaps due to a greater sense of responsibility and a desire for economic independence. As compared to all other occupational categories, children of parent's whose fathers are self-employed in agriculture are substantially more likely to seek training. The estimates show that employment in agriculture is even less attractive than working as a daily wage worker, and it appears that rural youth are keen on seeking out non-agricultural opportunities. Apart from these variables, and not surprising given the balance between the two groups, sex, age, caste, household income, agricultural land owned and poverty status have no bearing on participation.

In addition to the formal estimates, Table 4 provides information based on conversations with participants on their reasons for joining the scheme and their views on scheme satisfaction. It also contains information on why non-participants did not join the scheme. As far as participants are concerned, the most common reason to enroll is their expectation that the training will increase their income $(60 \%)$, followed by boosting their chances of acquiring an urban lifestyle $(55 \%)$, their inherent interest in the course on offer (55\%), the best available option at the time (52\%) and an increase in their social status (49\%). Although it was not mentioned as often, $22 \%$ expected that the course would help them join 'mainstream development' — which along with a desire to acquire an urban lifestyle may also be interpreted as a desire to move away from rural occupations and rural areas. While the NGO seems to have a number of well-educated personnel to deliver the course, post-scheme participation, about $27 \%$ rated the program as average and a large proportion $(64.6 \%)$ of the participants were not satisfied with the training.

Non-participants were asked who took the participation decision and to provide the single-most important reason for not-participating. In a majority of the cases (59\%), individuals decided not to attend of their own volition, parents decided in $27 \%$ of the cases and for the remainder (14\%), the training institute did not follow 
Table 3 Probability of participating in the training programs - marginal effects after probit (std. error)

\begin{tabular}{|c|c|c|c|}
\hline Variables & (1) & (2) & (3) \\
\hline \multicolumn{4}{|l|}{ Individual characteristics } \\
\hline Sex & $\begin{array}{l}-0.1012 * \\
(0.05773)\end{array}$ & $\begin{array}{l}-0.0513 \\
(0.06326)\end{array}$ & $\begin{array}{l}-0.0437 \\
(0.064)\end{array}$ \\
\hline Age & $\begin{array}{l}0.0016 \\
(0.01003)\end{array}$ & $\begin{array}{l}0.0046 \\
(0.01122)\end{array}$ & $\begin{array}{l}0.0033 \\
(0.01123)\end{array}$ \\
\hline Years of education & $\begin{array}{l}0.0381 * * * \\
(0.01449)\end{array}$ & $\begin{array}{l}0.0301 * * \\
(0.0156)\end{array}$ & $\begin{array}{l}0.0322 * * \\
(0.01574)\end{array}$ \\
\hline Married & $\begin{array}{l}0.1154 * \\
(0.07115)\end{array}$ & $\begin{array}{l}0.1570 * * \\
(0.07377)\end{array}$ & $\begin{array}{l}0.1464 * * \\
(0.07485)\end{array}$ \\
\hline Number of children & $\begin{array}{l}-0.0265 \\
(0.027)\end{array}$ & $\begin{array}{l}-0.0265 \\
(0.03211)\end{array}$ & $\begin{array}{l}-0.0244 \\
(0.02994)\end{array}$ \\
\hline Muslim & $\begin{array}{l}-0.1854 * \\
(0.10227)\end{array}$ & $\begin{array}{l}-0.0728 \\
(0.11726)\end{array}$ & $\begin{array}{l}-0.0835 \\
(0.11702)\end{array}$ \\
\hline Schedule caste & $\begin{array}{l}-0.0567 \\
(0.09846)\end{array}$ & $\begin{array}{l}0.0386 \\
(0.10443)\end{array}$ & $\begin{array}{l}0.0490 \\
(0.10476)\end{array}$ \\
\hline Other backward caste & $\begin{array}{l}-0.0197 \\
(0.10598)\end{array}$ & $\begin{array}{l}0.0594 \\
(0.11271)\end{array}$ & $\begin{array}{l}0.0661 \\
(0.11288)\end{array}$ \\
\hline \multicolumn{4}{|l|}{ Household characteristics } \\
\hline Age of father & - & $\begin{array}{l}-0.0007 \\
(0.00114)\end{array}$ & $\begin{array}{l}-0.0006 \\
(0.00113)\end{array}$ \\
\hline Age of mother & - & $\begin{array}{l}-0.0029 \\
(0.00337)\end{array}$ & $\begin{array}{l}-0.0028 \\
(0.00339)\end{array}$ \\
\hline Years of education of father & - & $\begin{array}{l}0.0120 * * * \\
(0.00496)\end{array}$ & $\begin{array}{l}0.0116 * * * \\
(0.00498)\end{array}$ \\
\hline Years of education of mother & - & $\begin{array}{l}0.0016 \\
(0.00698)\end{array}$ & $\begin{array}{l}0.0015 \\
(0.007)\end{array}$ \\
\hline Father's main occupation-unengaged in economic activity & - & $\begin{array}{l}0.0314 \\
(0.11412)\end{array}$ & $\begin{array}{l}0.0310 \\
(0.11452)\end{array}$ \\
\hline Father's main occupation-self-employed in non-agriculture & - & $\begin{array}{l}-0.2290 * * * \\
(0.07089)\end{array}$ & $\begin{array}{l}-0.2277 * * * \\
(0.07096)\end{array}$ \\
\hline $\begin{array}{l}\text { Father's main occupation-informal regular wage earning } \\
\text { (non-agriculture) }\end{array}$ & - & $\begin{array}{l}-0.2779 * * * \\
(0.0979)\end{array}$ & $\begin{array}{l}-0.2744 * * * \\
(0.09859)\end{array}$ \\
\hline $\begin{array}{l}\text { Father's main occupation-formal regular wage earning } \\
\text { (non-agriculture) }\end{array}$ & - & $\begin{array}{l}-0.0218 \\
(0.16016)\end{array}$ & $\begin{array}{l}-0.0098 \\
(0.16109)\end{array}$ \\
\hline Father's main occupation-daily wage worker & - & $\begin{array}{l}-0.1790 * * * \\
(0.05577)\end{array}$ & $\begin{array}{l}-0.1852 * * * \\
(0.05598)\end{array}$ \\
\hline Number of earning members in family & - & $\begin{array}{l}0.1610 * * * \\
(0.0625)\end{array}$ & $\begin{array}{l}0.1604 * * * \\
(0.06275)\end{array}$ \\
\hline Monthly household income in Rupees-pre-training & - & $\begin{array}{l}-0.0582 \\
(0.0605)\end{array}$ & $\begin{array}{l}-0.0594 \\
(0.06063)\end{array}$ \\
\hline Land owned in local unit (katha; 1 katha $=126 \mathrm{~m} 2)$ & - & $\begin{array}{l}0.0046 \\
(0.003)\end{array}$ & $\begin{array}{l}0.0043 \\
(0.00299)\end{array}$ \\
\hline Katcha (non-permanent) house & - & $\begin{array}{l}0.1285 \\
(0.08403)\end{array}$ & $\begin{array}{l}0.1354 \\
(0.0847)\end{array}$ \\
\hline Semi-Pucca (semi-permanent) house & - & $\begin{array}{l}0.1894 * * \\
(0.08528)\end{array}$ & $\begin{array}{l}0.1987 * * \\
(0.0857)\end{array}$ \\
\hline
\end{tabular}


Table 3 (continued)

\begin{tabular}{llll}
\hline Variables & $(1)$ & $(2)$ & $(3)$ \\
\hline Pucca (permanent) house-financed by government scheme & - & 0.1171 & 0.1355 \\
& & $(0.08864)$ & $(0.08926)$ \\
Below-poverty-line household & - & -0.0314 & -0.0380 \\
& & $(0.10253)$ & $(0.10274)$ \\
Self-help group household & - & $0.1607 * * *$ & $0.1657 * * *$ \\
Supply side & - & $(0.05149)$ & $(0.05153)$ \\
Distance to the training center $(\mathrm{km})$ & - & & $-0.0012 *$ \\
Observations & & & \\
Pseudo R-squared & 512 & 509 & $50.00069)$ \\
Log pseudo likelihood & -0.0303 & 0.1133 & 0.1175 \\
\hline
\end{tabular}

Standard errors in parentheses; $* * * p<0.01 ; * * p<0.05 ; * p<0.1$

up-for no clear reason or because they did not fulfill the eligibility conditions. ${ }^{21}$ The most commonly mentioned reason (21\%) for not joining was that the expected salary (Rs. 6000 a month) post-training was not attractive enough, followed by family responsibilities (18\%) and that they were seeking alternative educational opportunities (16\%). ${ }^{22}$ Distance to the training center was mentioned by $10 \%$ of the respondents and negative feedback about the course by $6.5 \%$.

\subsection{Impact of DDUGKY}

\subsubsection{Employment}

Tables 5 and 6 provide information on the impact of the training program on employment and earnings. Before commencement of the program, the employment rates of both groups were around 8-9\%, and conditional on working, monthly earnings were about Rs. 5000. Immediately after the end of the training, about $42 \%$ of the participants received job placements while the share of non-participants with jobs rose from 8.4 to $12.2 \%$. Formal, regression-based estimates which control for time trends and fixed effects yield a job offer employment impact estimate of 29 percentage points. The DDUGKY mandates that $70 \%$ of the graduates must be placed.

\footnotetext{
${ }^{21}$ Dropping these ineligible individuals from the non-participant sample increases comparability of the two groups but does not alter the impact of the program.

22 On one of the reasons for not participating, a focus group discussant mentioned, "You often don't get a job after training and even if you get a job the salary is not good. Many of my friends have completed the training but still they are without jobs. One of my friends got a job of Rs.6000/month in Patna. Now you tell me....is this job of any use? You can't save single paisa for yourself, and then there is no question of sending any money to parents. I can do a job in any shop near my village or might go far as the block headquarter and they will pay me 3000-4000 per month. This according to me is a much better option" [Translated from Hindi, Interviewed on July 26, 2016].
} 
Table 4 Reasons for participating and not participating and satisfaction
Participants

Reasons for participating in \%

Low opportunity cost/best option at that time 52

Increase in income

Increase in social status

Long-term future prospects

41

Urban life style 55

Join mainstream development 22

Inclination to service/jobs

Satisfaction with the training in \%

Very satisfied

Average

Not satisfied

64.6

(170)

Reasons for not participating in \% Non-part.

Own decision

Negative feedback from participants

Seeking educational opportunities

Unattractive salary prospects

Not interested

Distance to training center

Family decision

Family responsibilities

Marriage

Parents did not allow

Decision of training organization

Not BPL or SHG 
Table 4 (continued)

Participants

Under Age 1.5

Training organization did not contact

For those who participated, multiple responses were possible. Nonparticipants were asked to indicate who decided and the most important reason for not participating

Number of observations are reported in parentheses

Table 5 Pre-training, immediate post-training and current outcomes

\begin{tabular}{|c|c|c|c|c|c|c|}
\hline \multirow[t]{2}{*}{ Outcomes } & \multicolumn{2}{|c|}{ Pre-training } & \multicolumn{2}{|c|}{$\begin{array}{l}\text { Immediately } \\
\text { after training }\end{array}$} & \multicolumn{2}{|c|}{$\begin{array}{l}\text { Post-training } \\
\text { (at time of survey) }\end{array}$} \\
\hline & Part. & Non-part. & Part. & Non-Part. & Part. & Non-part. \\
\hline Employed (\%) & 8.74 & 8.4 & 41.8 & 12.5 & 16.0 & 12.5 \\
\hline$N$ & 23 & 22 & 110 & 33 & 42 & 33 \\
\hline Not offered a job (\%) & - & - & 58.2 & - & 58.2 & . \\
\hline$N$ & - & - & 153 & - & 153 & . \\
\hline Left job due to caste discrimination (\%) & - & - & - & - & 12.5 & . \\
\hline$N$ & & & & & 33 & \\
\hline $\begin{array}{l}\text { Left job-out-of-state state placement and low } \\
\text { salary }\end{array}$ & - & - & - & - & 13 & \\
\hline$N$ & & & & & 35 & \\
\hline Monthly earnings (Rupees) & $\begin{array}{l}426.8 \\
(1547)\end{array}$ & $\begin{array}{l}449 \\
(1780)\end{array}$ & - & - & $\begin{array}{l}933.5 \\
(2456)\end{array}$ & $\begin{array}{l}727 \\
(2218)\end{array}$ \\
\hline Monthly earnings if employed (Rupees) & $\begin{array}{l}4881 \\
(2404)\end{array}$ & $\begin{array}{l}5372 \\
(3435)\end{array}$ & - & - & $\begin{array}{l}5845 \\
(3023)\end{array}$ & $\begin{array}{l}5791 \\
(3168)\end{array}$ \\
\hline
\end{tabular}

The total number of observations is 263 for participants and 263 for non-participants. Standard deviations for continuous variables are in parentheses. Post-training refers to outcomes between 2 and 6 months after training

However, as compared to the international literature on the estimates of vocational training programs on employment rates, the placement of $42 \%$ of the candidates and an impact of 29 percentage points is astounding. However, at the time of the survey, that is, about 2-6 months after the end of the training we find that the difference in the employment rate across the two groups is only 3.4 percentage points which is at par with the estimates reported in McKenzie (2017). Regardless of the statistical approach used (also see Table 9), that is cross section estimates that control for individual and household traits or fixed effect estimates, the impact of the training program on employment is not statistically different from zero. The magnitude ranges from 3 to 3.4 percentage points. 


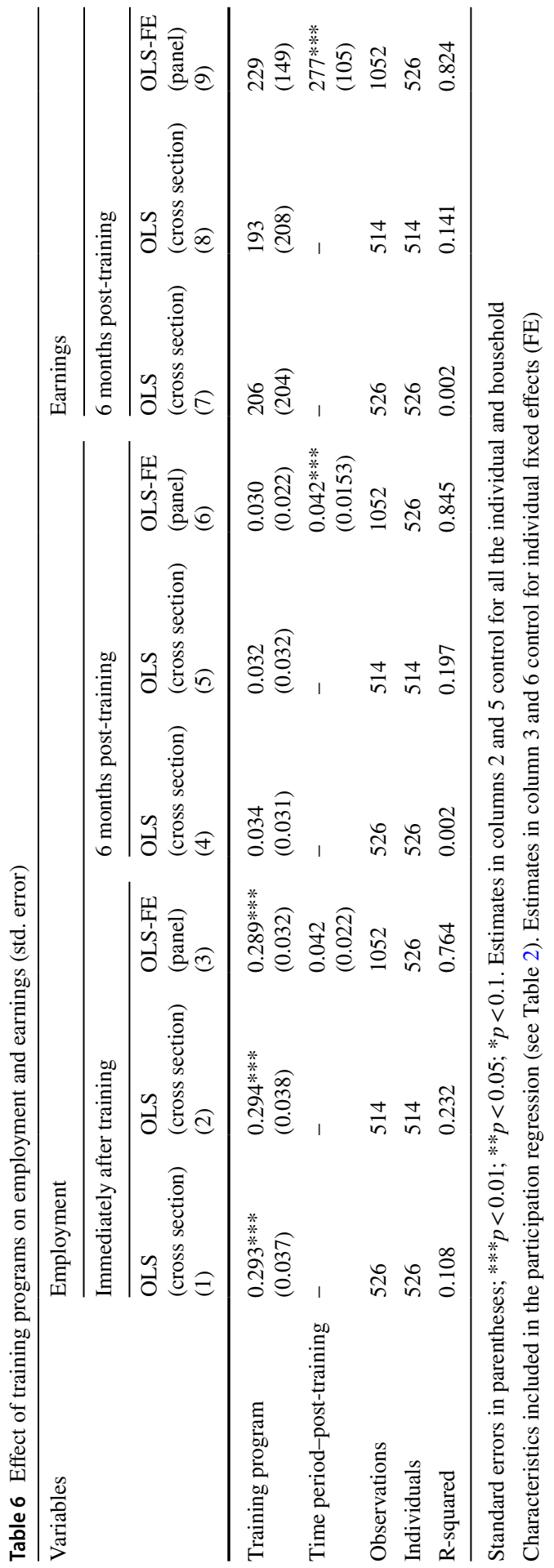


The sharp drop in employment rates within a few months after training is intriguing and led us to engage in deeper conversations with all the participants. The entire set of 153 trainees who had not been placed after training remained unemployed at the time of the survey. Of the 110 who had received placements, 42 were continuing in their positions. Of the remainder who had been placed, 33 fled their positions or were forced to leave their jobs, some within days others within a few weeks. The ostensible reason appears to be discrimination at the hands of their employers and employees. The respondents reported that they were treated harshly due to their low-caste status, most of the time by other employees and at times by employers. For instance, they were not allowed to use toilets and kitchens and to eat or sit in common areas designated for such purposes. ${ }^{23}$ The remaining 35 participants had been offered out-of-state placements (in urban areas) and despite the desire to access an urban lifestyle and seek out non-agricultural opportunities, they rejected these offers as the salaries offered were deemed to be too low as compared to living costs. ${ }^{24}$ Some rejected offers on the spot while others worked for a short while before returning to their homes.

\subsubsection{Quality and Nature of Jobs}

While there is no discernible effect of the program on employment status, it is possible that the training program translates into better quality of jobs as captured by higher wages and/or enhances the ability of participants to access non-agricultural jobs. Information on the impact of the training scheme on monthly earnings is provided in Tables 5 and 6 . Earnings of participants does seem to be higher, however, regardless of whether we control or not for various characteristics or rely on the fixed effects as opposed to the cross section estimates, we are unable to detect a statistically significant impact of the training program on earnings. The occupational distribution of participants and non-participants is displayed in Table 7. There are clear differences across the two groups. While the occupational distribution of the non-participants does not exhibit much variation over time, there is a clear change in the case of participants. All those who participated and are now employed are working in the informal, non-agriculture sector in wage paying positions. Based on their desire to move away from agricultural occupations, the post-training occupational distribution is a positive development.

\footnotetext{
${ }^{23}$ For instance during a focus group discussion a participant commented-“Almost immediately after joining the job, three of us were sent to one branch office of the company for hands on training for 10 days. But, we could attend that training for only 3 days as we were not allowed to use any public facility in that office. We were neither allowed to use any of the washrooms nor even touch any tap, nor enter the canteen. When we asked the reason for this behavior, we were told that we belong to low caste. So after three days we resigned from the job and returned to our village" [Translated from Hindi, Interviewed on July 25, 2016].

24 During discussions, the respondents explained that if they are placed anywhere outside their home districts then expected expenditure on house rent would lie between Rs. 2500 and 3000 . They expect to incur between Rs. 3000 and 3500 on food and other items to meet basic needs. So with a salary of Rs. 6000 , they do not expect to remit more than Rs. 500 to their families and this is too small an amount to warrant an out-of-district placement. They repeatedly mentioned that they would be more than happy to work for a salary of Rs. 6000 within the district.
} 


\subsubsection{Rates of Return}

The training course offered by the PIA in the current analysis was budgeted at Rs. 61,304 per participant. While some of the payments such as transport are based on actuals, and others only need to be paid out if targets are met, the tuition cost and the living costs of the participants or in other words the minimum cost that has to be incurred by the government for the three-month residential training course is Rs. 37,439. Both the minimum cost and the budgeted cost are likely to underestimate the total cost of producing a trained graduate as these don't include payments to various other stakeholders involved in the scheme. Based on the available macro data on the total resources expended on the DDUGKY since inception and the number of trained individuals, the per person cost of training a graduate is estimated to be Rs. 217,210. We work with these three cost estimates to provide a sense of the rate of return to the current training course based on achieving different employment impacts (see Table 8).

Based on the minimum cost and the estimated 3\% employment effect (Table 6, column 3), the expected annual benefit on an annual salary of Rs. 72,000 amounts to Rs. 2160. Assuming a generous 20 -year return period, this translates into an underwhelming internal rate of return of $1 \%$. If individuals who had been placed but left their jobs due to discrimination had maintained their positions then the employment effect of the training course would have been $12.3 \%$. Keeping all other parameters fixed, this translates into a healthy internal rate of return (IRR) of $23.3 \%$. If we assume that the appropriate cost measure is the budgeted cost, then the IRR drops to $-3.1 \%$ for the $3 \%$ employment effect and $13.2 \%$ for the employment effect if there had been no discrimination. If we work with the estimated cost per trained graduate obtained from the macro-level data, then the corresponding returns for the low and high employment effects are -12.1 and -1.9 , respectively. Based on this macro-level cost estimate, the employment effects needs to be at least $15 \%$ to break even and $30.6 \%$ in order to deliver an IRR of $8 \%$ which may be considered the opportunity cost of capital.

The DDUGKY scheme requires a $70 \%$ job placement rate at an annual minimum salary of Rs. 72,000 from the PIA. This is clearly an impossible target, setting aside the issue of whether such dictated job creation approaches are at all sensible. Nevertheless, what these calculations show is that on the basis of the full-cost of producing a trained graduate an employment impact estimate of about $15 \%$ yields a nonzero rate of return. This is not an impossible target and in the case of the training program under scrutiny the employment impact corrected for discrimination $(12.3 \%)$ is not so far from the employment impact needed to deliver positive returns.

\section{Concluding Remarks}

Since 2014, the government of India has launched a number of skills training and job placement schemes. While substantial resources are being expended on this and similar schemes, there is very little evidence on their effectiveness in reaching their intended target and in generating employment opportunities.

This paper focused on evaluating the effects of one of the most prominent allIndia schemes, the 'Deen Dayal Upadhayay Grameen Kaushal Yojana' (DDUGKY), 
Table 7 Pre-training and post-training-occupational distribution

\begin{tabular}{lccccc}
\hline Outcomes & \multicolumn{2}{c}{ Pre-training } & & \multicolumn{2}{l}{$\begin{array}{l}\text { Post-training } \\
\text { (at time of survey) }\end{array}$} \\
\cline { 2 - 3 } \cline { 5 - 6 } Nature of employment & Part. & Non-part. & & Part. & Non-part. \\
\hline Unengaged in economic activity & 91.3 & 91.6 & & 84.0 & 87.4 \\
Self-employed in agriculture & 0.40 & 0.40 & & - & - \\
Self-employed in non-agriculture & - & 2.28 & & - & 3.44 \\
Informal regular wage, non-agri. & 2.28 & 1.52 & & 16.0 & 1.91 \\
Formal regular wage, non-agri. & 0.38 & 0.38 & & - & 0.38 \\
Daily wage worker & 5.70 & 3.80 & & - & 6.87 \\
\hline
\end{tabular}

which targets rural youth from poor families. That is, a group which is most likely to face a skills gap and for whom such skills training programs should be particularly effective. We focused on the effects of the scheme in rural Bihar, one of India's poorest states. The analysis was based on comparing individuals who had attended a training course sponsored through the scheme with individuals who had applied but did not eventually attend the training.

The empirical approach delivered comparable groups. Our assessment showed that the scheme is very well targeted, and more than $90 \%$ of those who attended the training and showed an interest in the scheme belonged to below-poverty-line families. While the NGO appeared to have well-qualified personnel, the bulk of the participants $(64.6 \%)$ were not satisfied with the training they had received. With regard to employment effects, $42 \%$ of the graduates were placed immediately after the training, which translates into a $29 \%$ percentage point impact of training on employment. However, these gains were short-lived and within 2-6 months after training, the impact of the scheme on employment was statistically not different from zero. About a third of the placed graduates left their jobs due to caste discrimination and a third exited as the salaries offered were too low as compared to their expected living costs. While employment effects were zero, the training did help graduates move from agricultural to non-agricultural positions.

The analysis presented here focused on one training course in one district of rural Bihar. While this paper does not paint a very optimistic picture of scheme-induced employment effects nor is it overtly negative about the scheme itself. Indeed, in the current case the positive effects of the scheme appear to have been partially undone by deep-rooted discrimination. It is entirely possible that other courses offered in other parts of the country are able to achieve higher placement rates and that trained graduates are not subject to post-placement discrimination. ${ }^{25}$ Notwithstanding this possibility, what this paper highlights is the urgent need for credible analyses of the slew of skills and job training programs that have recently been launched by the government. These analyses should focus not only on initial job placement

\footnotetext{
25 The placement rate of $42 \%$ achieved by the current course immediately after training is not very different from the macro-figures for DDUGKY which show an initial job placement rate of $49.6 \%$.
} 
Table 8 Internal rate of return-private perspective

Cost/benefit Combination (Rs.) Returns ${ }^{\mathrm{h}}$

(Rs.)

(i) Minimum cost of three-month residential training ${ }^{\mathrm{a}}$

37,439

(i)-(iv)

1.0

(ii) Budgeted cost of three-month residential training ${ }^{\mathrm{b}}$

61,304

(i) $-(\mathrm{v})$

(iii) Cost of training based on total budget/trained

217,210

(ii)-(iv) individuals ${ }^{c}$

(iv) Annual expected benefit-employment effect $(3 \%)^{\mathrm{d}} \quad 2160$

(ii)-(v)

(v) Annual expected benefit-employment effect $(12.3 \%)^{\mathrm{e}} \quad 8856$

(iii)-(iv)

(vi) Annual expected benefit-employment effect $(15.0 \%)^{\mathrm{f}} \quad 10,900$

(iii) $-(\mathrm{v})$

$-1.9$

(vii) Annual expected benefit-employment effect

22,500

(iii)-(vi)

0.0 $(30.6 \%)^{\mathrm{g}}$

(iii)-(vii)

8.0

${ }^{\text {a }}$ The minimum cost includes the tuition and boarding and lodging costs of one individual who attends the 3-month course offered by the project implementing agency

${ }^{\mathrm{b}}$ The budgeted cost is the potential amount which may have to be paid out to the project implementing agency and includes items to be paid out in actuals and performance related payments

${ }^{\mathrm{c}}$ The cost figure here is based on total DDUGKY costs and individuals trained since inception till end2016

${ }^{\mathrm{d}}$ The expected benefit is based on annual earnings of Rs. 72,000 and a 3\% increase in the probability of obtaining a job due to the training scheme

${ }^{\text {e}}$ The expected benefit is based on annual earnings of Rs. 72,000 and a 12.3\% increase in the probability of obtaining a job, that is, the increase in employment probability if there had been no discrimination

${ }^{\mathrm{f}}$ The expected benefit based on annual earning of Rs. 72,000 and a $15 \%$ increase in the probability of obtaining a job due to the training scheme. This is the employment effect which would lead to breakeven based on an estimated cost of Rs. 217,210 per trained graduate

${ }^{\mathrm{g}}$ The expected benefit based on annual earning of Rs. 72,000 and a $32 \%$ increase in the probability of obtaining a job due to the training scheme. This is the employment effect which would lead to a return of $8.5 \%$ on an estimated cost of Rs. 217,210 per trained graduate. The rate of return on a 1-year term deposit in selected Indian banks in 2017 is about $8 \%$. This may be viewed as the opportunity cost of capital

${ }^{\mathrm{h}}$ The duration of the payback period is set at 20 years and benefits are fixed for this duration

but also examine employment status after a time lag. Finally, while simply dictating job creation through such skills training courses and demanding $70 \%$ placement is unlikely to succeed, the analysis presented here shows that employment effects in the range of about $15 \%$ are likely to deliver a nonzero return.

Open Access This article is distributed under the terms of the Creative Commons Attribution 4.0 International License (http://creativecommons.org/licenses/by/4.0/), which permits unrestricted use, distribution, and reproduction in any medium, provided you give appropriate credit to the original author(s) and the source, provide a link to the Creative Commons license, and indicate if changes were made.

\section{Appendix}

See Table 9. 


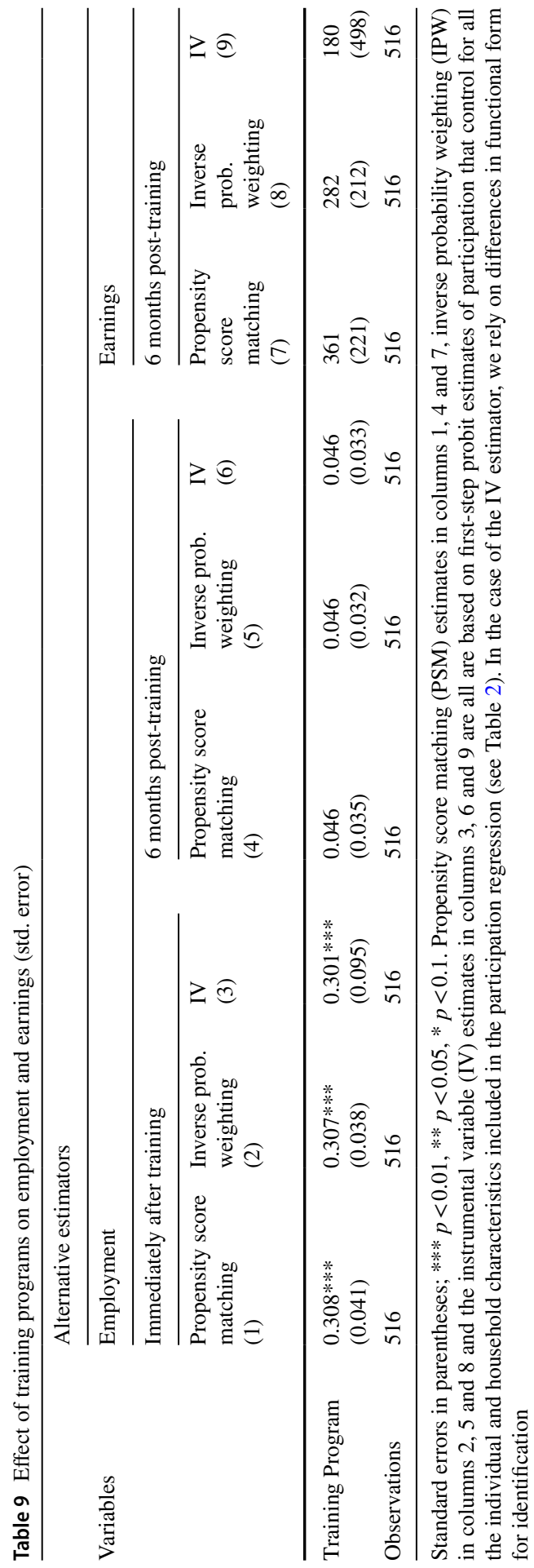




\section{References}

Acevedo, P., G. Cruces, P. Gertler, and S. Martinez. 2017. "Living Up to Expectations: How Job Training Made Women Better Off and Men Worse Off." NBER Working Paper No. 23264, NBER, Boston, MA.

Alzua, M.L., G. Cruces, and C. Lopez. 2016. Long-Run Effects of Youth Training Programs: Experimental Evidence from Argentina. Economic Inquiry 54(4): 1839-1859.

Attanasio, O., A. Kugler, and C. Meghir. 2011. Subsidizing Vocational Training for Disadvantaged Youth in Colombia: Evidence from a Randomized Trial. American Economic Journal: Applied Economics 3(3): 188-220.

Attanasio, O., A. Guarın, C. Medina, and C. Meghir. 2017. Vocational Training for Disadvantaged Youth in Colombia: A Long-Term Follow-Up. American Economic Journal: Applied Economics 9(2): 131-143.

Betcherman, G., A. Dar and K. Olivas. 2004 Impacts of Active Labor Market Programs: New Evidence from Evaluations with Particular Attention to Developing and Transition Countries. Social Protection Discussion Series Paper No. 0402. Washington D.C: The World Bank.

Björklund, A. 1994. Evaluations of Labour Market Policy in Sweden. International Journal of Manpower 15(5): 16-31.

Card, D., P. Ibarrarán, F. Regalia, D. Rosas-Shady, and Y. Soares. 2011. The Labor Market Impacts of Youth Training in the Dominican Republic: Evidence from a Randomized Evaluation. Journal of Labor Economics 3(2): 267-300.

Cho, Y., Kalomba, D., Mobarak, A.M. and Orozco, V. 2013. Gender Differences in the Effects of Vocational Training: Constraints on Women and Drop-Out Behavior. IZA Discussion Paper No. 7408. Bonn: Institute for the Study of Labor.

Dar, A., and Z. Tzannatos. 1999. Active labor market programs: A review of the evidence from evaluations. Social Protection Discussion Paper Series, No. SP 9901, Washington, DC: The World Bank.

De Koning, J. 2005. Active Labour Market Policies: Relevance, Expenditure and Effectiveness. SEOR Working Paper 2005/2. Rotterdam: SEOR, Erasmus University Rotterdam.

Diaz, J. J., and D. Rosas. 2016. Impact Evaluation of the Job Youth Training Program ProJoven. InterAmerican Development Bank Working Paper No. 693.

Forslund, A., and A. Krueger. 1997. An Evaluation of Swedish Labor Market Policy: New and Received Wisdom. In The Welfare State in Transition: Reforming the Swedish Model, ed. R. Freeman, R. Topel, and B. Swedenborg. Chicago: University of Chicago Press.

Heckman, J.J., R.J. Lalonde, and J.A. Smith. 1999. The Economics and Econometrics of Active Labor Market Programs. In Handbook of Labor Economics 3(A), ed. O.C. Ashenfelter and D. Card, 1865-2097. Amsterdam: Elsevier.

Hirshleifer, S., D. McKenzie, R. Almeida, and C. Ridao-Cano. 2016. The Impact of Vocational Training for the Unemployed. Experimental Evidence from Turkey. Economic Journal 126(597): 2115-2146.

Honorati, M. 2015. The Impact of Private Sector Internship and Training on Urban Youth in Kenya. World Bank Policy Research Working Paper 7404. Washington D.C: The World Bank.

Ibarrarán, P., L. Ripani, B. Taboada, J. Villa, and B. Garcia. 2014. Life Skills, Employability and Training for Disadvantaged Youth: Evidence from a Randomized Evaluation Design. IZA Journal of Labor and Development 3(10): 1-24.

Kluve, J. 2010. The Effectiveness of European Active Labour Market Policy. Labour Economics 17(6): 904-918.

Maitra, P., and S. Mani. 2017. Learning and Earning: Evidence from a Randomized Evaluation in India. Labour Economics 45: 116-130.

McKenzie, D. 2017. How Effective are Active Labor Market Policies in Developing Countries? A Critical Review of Recent Evidence. The World Bank Research Observer 32(2): 127-154.

Meager, N. 2009. The Role of Training and Skills Development in Active Labour Market Policies. International Journal of Training and Development 13(1): 1-18.

Mitra, A. and S. Verick. 2013. Youth Employment and Unemployment: An Indian Perspective. ILO AsiaPacific Working Paper Series, New Delhi: ILO.

Ministry of Rural Development, Government of India. 2016. DDU-GKY Program Guidelines. New Delhi, India. http://ddugky.gov.in/sites/default/files/SOP/mail\%20ddugky\%20guidelines\%20wit h\%20cover_0.pdf. 
Ministry of Skill Development and Entrepreneurship, Government of India. 2015. National Policy for Skill Development and Entrepreneurship. New Delhi, India. http://www.skilldevelopment.gov.in/ assets/images/Skill\%20India/policy\%20booklet-\%20Final.pdf.

Ministry of Labour \& Employment, Government of India. 2014. Report on Education, Skill Development and Labour Force. Chandigarh, India. http://labour.nic.in/sites/default/files/Report\%20Vol\%203\%20 final.pdf.

Reserve Bank of India. 2016. Handbook of Statistics on Indian Economy. https://www.rbi.org.in/scripts/ PublicationsView.aspx?id=15283. Accessed on July 7, 2017.

Publisher's Note Springer Nature remains neutral with regard to jurisdictional claims in published maps and institutional affiliations. 